\title{
Rivers's Postulates Fulfilled for Blue Catfish Alloherpesvirus
}

\author{
Vandana Dharan, Suja Aarattuthodi* \\ Thad Cochran National Warmwater Aquaculture Center, Mississippi State University, Stoneville, USA
}

Email address:

vd302@msstate.edu (V. Dharan), bsa122@msstate.edu (S. Aarattuthodi)

${ }^{*}$ Corresponding author

\section{To cite this article:}

Vandana Dharan, Suja Aarattuthodi. Rivers's Postulates Fulfilled for Blue Catfish Alloherpesvirus. Frontiers in Environmental Microbiology. Vol. 7, No. 3, 2021, pp. 80-84. doi: 10.11648/j.fem.20210703.12

Received: November 2, 2021; Accepted: November 18, 2021; Published: November 24, 2021

\begin{abstract}
Blue catfish alloherpesvirus (BCAHV) is a strain of ictalurid herpesvirus-1 belonging to the family Alloherpesviridae. A detailed study on the pathogenesis of this virus revealed that it causes significant mortalities in blue catfish fingerlings and could be problematic with hybrid catfish production. The genome of BCAHV has $94 \%$ similarity with channel catfish virus (CCV) and these herpesviruses are a major threat to the hatchery and nursery phases of fish production. Even though, several studies have been caried out regarding the virulence, immune responses, and factors influencing infection, Rivers's postulates have not been verified for BCAHV infection so far. Validation of Rivers's postulates is essential to confirm virus as the causative agent of a disease. Testing and verification of Rivers's postulates are also essential to decide on treatments or while establishing proactive management strategies. In the current study, we tested Rivers's postulates to validate BCAHV as the etiologic agent of the infection in blue catfish fingerlings. The infected blue catfish tissues were processed, filtered, inoculated onto channel catfish ovary (CCO) cells, and virus-specific cytopathic effects were observed. The cell culture propagated-BCAHV produced comparable infection in naïve blue catfish when exposed via immersion and was reisolated from the infected fish. Specific immune responses against BCAHV were observed, when survivors from an initial virus exposure were challenged with wild type virus after 45 days. Here, Rivers's postulates were satisfied for BCHAV infection in blue catfish proving BCAHV as the etiological agent of infection.
\end{abstract}

Keywords: Rivers's Postulates, Blue Catfish Alloherpesvirus, Cytopathic Effects, Immune Response

\section{Introduction}

Infectious viral diseases are detrimental to intensive aquaculture production and result in substantial economic and trade losses hindering the expansion of global aquaculture [1]. Some of the viral infections enlisted by the World Organization for Animal Health (OIE) are required to be reported to state animal health officials [2-4]. In such cases, the producer has to destroy the entire infected stock and disinfect the farm/hatchery further exacerbating the financial losses. Viral infections are difficult to control and moreover the aquaculture settings make it even harder compared to other livestock production systems [1]. Intensification of aquaculture practices and expansion of global live-fish trade further pave way for the emergence of new viral pathogens and reemergence of the existing ones $[1,5]$.

Viruses are obligate intracellular parasites that require host cell machinery to propagate and cause infections [6-7]. These submicroscopic infectious agents can infect all life forms from bacteria to higher vertebrates. Dmitri Ivanovsky in 1892 reported the first viral disease in tobacco plants, which remained obscure until Martinus Beijerinck in 1898 described the causative agent as tobacco mosaic virus [8]. The debate over 'live or dead status of virus' is being held for many years [9]. Virus particles are lacking organelles for energy production including ribosomes and therefore not capable to reproduce in culture media [10]. Since viruses require host cells for replication, viral disease diagnosis relied on susceptible cell cultures as early as 1900s [10-11]. Viruses are capable of inducing alterations in cellular characteristics, collectively known as cytopathic effects (CPEs) [10]. Accordingly, cell cultures are considered as the 'gold standard' in virology $[11,12]$.

Confirmation regarding the pathogen causing an infection is 
absolute requirement for decision on treatment or management strategies. For the identification and confirmation of a pathogen responsible for a disease, German physician, Robert Koch articulated a set of frameworks including four postulates [13]. Koch's postulates embrace the association of an organism with the disease at all times, isolation of the organism from the diseased host and ability to grow in pure culture, reproducing the same disease when a pure culture of the organism is introduced into healthy host, and re-isolation of the same organism from the experimentally infected host [13]. These postulates facilitated scientific foundation for the epidemiology of many infectious diseases. While more promising in verifying bacterial infections, Koch's postulates were inadequate to validate viruses as the etiologic agents of an infection. Therefore, Thomas Rivers [14] modified Koch's postulates to accommodate viruses as potential causative agents of diseases in the host. Accordingly, six criteria have to be fulfilled to establish virus as the cause of a disease. The causative relationship between a virus and disease are stated as isolation of the virus from the diseased host, cultivation of virus in host cells, proof of filterability, production of comparable disease when the cultivated virus is used to infect experimental animals, reisolation of the same virus from the infected experimental animals, and detection of specific immune responses to the virus. Validation of theses six postulates are crucial to verify the causation of a disease as a virus.

Ictalurid herpesviruses are the most important viral pathogens infecting catfish aquaculture [15-18]. Blue catfish alloherpesvirus (BCAHV) is a novel strain of ictalurid herpesvirus-1 (S98-675) isolated from blue catfish (Ictalurus furcatus) fingerlings in 1998 [19]. This virus was reported to be genetically similar ( $\sim 94 \%)$ to channel catfish virus [20]. A comprehensive study on the pathogenesis of BCAHV revealed its host preferences, virulence, and the factors influencing disease outbreaks [18]. In the current study, Rivers's postulates were tested and verified for BCAHV infection to confirm the causative agent as a virus.

\section{Materials and Methods}

\subsection{Virus, Cell Line, and Fish Used in the Study}

A cell culture viable isolate of BCAHV (S98-675) was received from Dr. Larry Hanson, College of Veterinary Medicine, Mississippi State University. The virus was propagated in $\mathrm{CCO}\left(\mathrm{ATCC}^{\circledR} \mathrm{CRL}^{\circledR} 2772\right)$ cells grown in Leibovitz's L-15 media (Corning cellgro, Manassas, VA) supplemented with $10 \%$ fetal bovine serum (FBS; Gibco-Life Technologies, Grand Island, NY) at $25^{\circ} \mathrm{C}$. Once the cell monolayer was completely destroyed, the virus laden-cells were harvested, and stored using previously published protocols $[18,21]$. Naïve blue catfish (10 days post hatch (dph)) were procured from USDA-ARS Warmwater Aquaculture Research Unit, Stoneville, MS. Fry were fed with $65 \%$ protein diet and maintained till the virus challenge. All challenge protocols were approved by the Mississippi State University Institutional Animal Care and Use Committee (IACUC-20-091).

\subsection{Isolation of BCAHV from Diseased Blue Catfish}

Healthy, blue catfish fingerlings were experimentally infected via immersion with cell line-propagated BCHAV at a concentration of $10^{3.5} \mathrm{TCID}_{50} / \mathrm{ml}$ for $3 \mathrm{hrs}$ [22]. Fish were observed for BCAHV-associated clinical signs and mortalities [18]. Moribund fish exhibiting clinical signs were removed from the tanks and euthanized with $300 \mathrm{mg} / \mathrm{l}$ tricaine methane sulfonate (MS-222) bath. Spleen and kidney tissues were aseptically dissected out from the fish and homogenized in 1X HBSS buffer using a tissuelyser (Qiagen, Germantown, MD). The tissue suspension was centrifuged at $8000 \mathrm{~g}$ for $4 \mathrm{~min}$.

\subsection{Propagation of BCAHV in Host Cells, and Proof of Filterability}

The supernatant from the tissuelysed suspension was filtered through $0.22 \mu \mathrm{m}$ syringe filters, inoculated onto healthy CCO cell monolayers, and incubated at $25^{\circ} \mathrm{C}$. Triplicates and control cells without virus were maintained. Cells were monitored daily under inverted microscope (Zeiss Primovert, White Plains, NY) for virus-specific CPEs. Once the cell monolayer was completely detached from the culture surface, the virusladen cells along with the media were fully harvested. This inoculum was passed through $0.22 \mu \mathrm{m}$ syringe filters and the filtrate was further inoculated onto confluent healthy CCO cells. A blind passage was also carried out and cells were monitored daily for virus-specific CPEs [18].

\subsection{Production of Comparable Disease in the Susceptible Host}

The CCO cells inoculated with BCAHV were harvested once the cytopathic effects were visible. The virus-laden cells were subjected to three freeze-thaw cycles, cellular debris removed by centrifugation at $4696 \mathrm{~g}$ for $10 \mathrm{~min}$ and stored at $-80^{\circ} \mathrm{C}$ till use [21]. Naïve blue catfish fingerlings $(\mathrm{n}=50$ fish/tank, average wt. $\sim 1.45 \mathrm{gm} ; 75 \mathrm{dph}$ ) were challenged with BCAHV at a concentration of $10^{3.5} \mathrm{TCID}_{50} / \mathrm{ml}$ via immersion challenge. During the challenge, water flow to the tanks was stopped. Eight virus-exposed tanks were maintained in addition to control tanks. After the fish were exposed to BCAHV for $3 \mathrm{hrs}$, the water flow was reinstated and the feeding started day after. Fish were observed daily for BCAHV-associated clinical signs and mortalities. Percent mortality was statistically analyzed. Histopathological analysis of the infected tissues was carried out [18].

\subsection{Re-isolation of the Virus}

Moribund fish infected with BCAHV from the previous challenge were collected and euthanized using MS-222. Kidney and spleen tissues were aseptically removed and macerated in $1 \mathrm{X}$ HBSS using a tissuelyser. The processed tissue suspension was centrifuged at $8000 \mathrm{~g}$ for $4 \mathrm{~min}$. The supernatant was filtered through $0.22 \mu \mathrm{m}$ syringe filters and the filtrate was inoculated onto healthy $\mathrm{CCO}$ cell monolayers. Cells were monitored daily for the presence of 
CPEs. Control cells were also maintained.

\subsection{Detection of Specific Immune Responses to BCAHV Infection}

After 45 days of virus exposure, survivor fish from the previous challenge were distributed equally among four different tanks ( $\mathrm{n}=15 \mathrm{fish} / \mathrm{tank}$ ). These fish were exposed to BCAHV $\left(10^{3.5}\right.$ TCID $\left._{50} / \mathrm{ml}\right)$ following similar challenge protocol. Naïve blue catfish fingerlings from the same spawn were also exposed to the virus. Controls were maintained. Mortalities were recorded for 14 days post virus exposure and results were statistically analyzed to compare the results.

\section{Results and Discussion}

Modification of the Koch's postulates by Rivers were necessary to test and verify viruses as etiologic agents since some of the Koch's postulates were incompatible in the case of viral diseases. For example, according to the first postulate, the pathogens must be present in abundance in all the hosts suffering from the disease but should not be found in healthy hosts. This criterion contradicts some viral infections where, it is not compulsory to establish the presence of the virus as a cause of an infection. For example, paralysis associated with poliovirus is not seen in all individuals exposed to the virus or asymptomatic carrier states exist in many viral diseases. Additionally, viruses require host cells for propagation and cannot be grown in pure media [23].

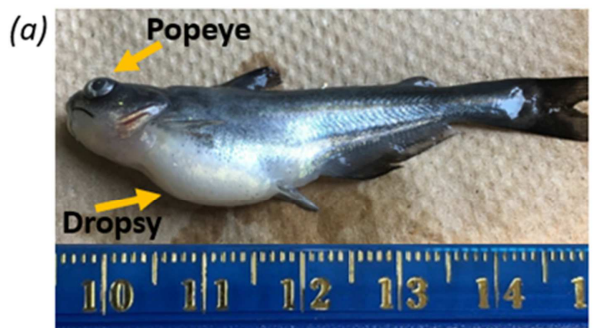

(b)

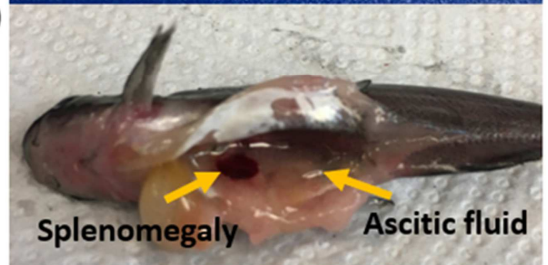

Figure 1. Clinical signs of BCAHV infection exhibited by blue catfish fingerlings. (a) External clinical signs such as dropsy (distended abdomen) and exophthalmia (popeye), and (b) internal clinical signs such as splenomegaly and straw-colored ascitic fluid were observed in the infected fish.

The first Rivers's postulate is the isolation of virus from an infected host. In this study, the BCAHV infected blue catfish exhibited behavioral changes such as reduced feed intake, excessive mucus production, and loss of equilibrium. External clinical signs were mild to moderate exophthalmia and distended abdomen (Figure 1). Internal clinical signs included fluid-filled peritoneal cavity, congested spleen, and swollen anterior and posterior kidney (Figure 1). These clinical signs were comparable to those associated with $\mathrm{CCV}$ infections in channel catfish [15, 24-25]. Both BCAHV and $\mathrm{CCV}$ are ictalurid herpesvirus 1 strains belonging to Alloherpesviridae, sharing 94\% genomic similarity [15-16, $18,20]$. These similarities explain the comparable clinical signs of BCAHV infection.

Inoculation of the filtrate from the spleen and kidney tissues of the infected fish produced CPEs in CCO cells within $72 \mathrm{hrs}$ of incubation at $25^{\circ} \mathrm{C}$ confirming the presence of BCAHV infection. Virus-specific CPEs included rounding of cells, syncytia and plaque formation, destruction of cell monolayer, and complete detachment of cells from the culture surface (Figure 2). The CPEs were similar to those produced by $\mathrm{CCV}$ in $\mathrm{BB}$ cells [24-25]. Close resemblance in CPEs produced by BCAHV and $\mathrm{CCV}$ infections can be attributed to their genetic similarity [20]. The CCO cell line used for propagating the virus is originated from ictalurid catfish and is susceptible to ictalurid catfish viruses [25]. Since the viruses from Alloherpesviridae are host-specific, the selection of a permissive cell line for such studies is of utmost importance. Cytopathic effects caused by BCAHV were consistent even after 2-3 serial passages in cell culture eliminating toxins as a potential causative agent of this infection. Prior to inoculation onto the cell cultures, the BCAHV suspension was passed through $0.22 \mu \mathrm{m}$ filters, which was used for channel catfish virions $(175-200 \mathrm{~nm})$ in previous studies [25-26]. Hence, the first three criteria of Rivers's postulates namely isolation of the virus from diseased host, cultivation of virus in host cells, and the filterability of the infectious agent have been met for BCAHV infection.
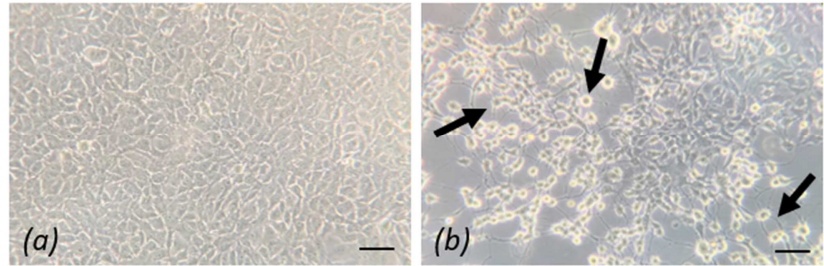

Figure 2. Cytopathic effects produced by BCAHV in channel catfish ovary (CCO) cells. The CPEs involved rounding of cells, syncytia (cell clumping), plaques, and detachment of cells from the culture surface. (a) Control cells, (b) BCAHV infected cells (scale bar-10 $\mu \mathrm{m}$ ).

When exposed to BCAHV via immersion challenge, the naïve blue catfish fingerlings showed $\sim 80 \%$ mortality (Figure 3). Fish mortality initiated within 3 days and continued until 10-11 days with a peak in 5-7 days of BCAHV exposure. Gross clinical signs exhibited by the infected fish were similar to any natural BCAHV infections [18-20]. Histopathological analysis of infected tissues revealed that changes were more prominent in the spleen and kidney tissues correlating to internal clinical signs of BCAHV infection [18]. Hence, the fourth postulate i. e. production of comparable disease in susceptible hosts was verified. The virus was reisolated from the spleen and kidney tissues of infected blue catfish and was confirmed by the BCAHV-specific CPEs in host 
cells. Morphologic cellular changes were consistent even after subsequent passages including a blind passage further confirming the presence of virus as the causation of the disease and excluded any chances of toxin as the infective agent [27]. Re-isolation of the virus confirmed that the infection and associated mortalities were due to the administered pathogen and excluded the likelihood of any other agents.

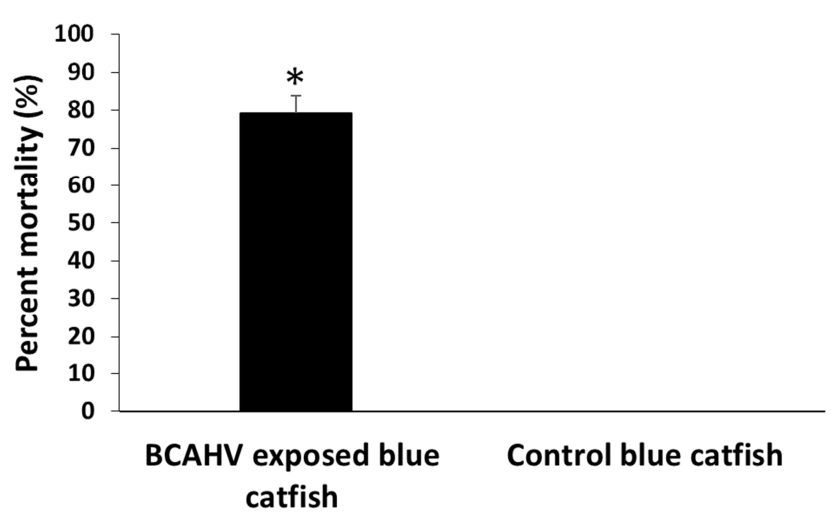

Figure 3. Percent mortality of blue catfish fingerlings when challenged with $B C A H V\left(10^{3.5} T_{C I D} / \mathrm{ml}\right)$. Data represent average mortality $\pm S E M$. * indicates statistically significant difference in the means $(p \leq 0.05)$.

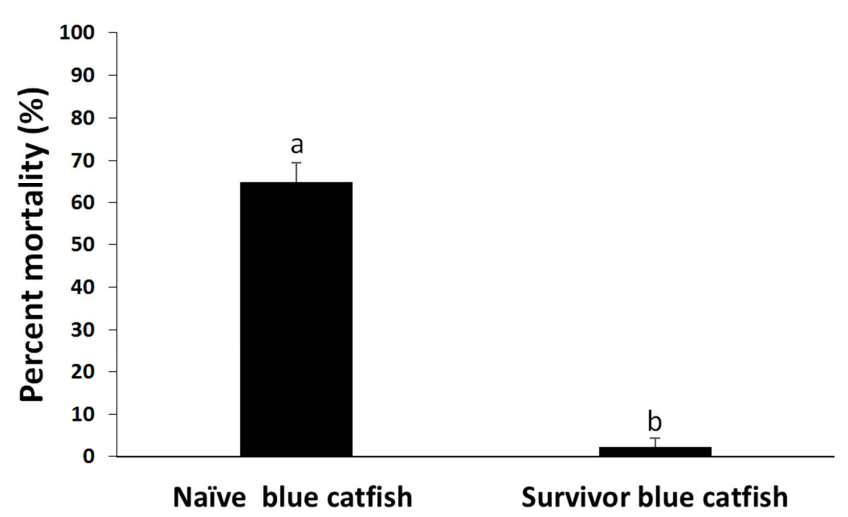

Figure 4. Percent mortality in naïve blue catfish fingerlings and survivors from previous $B C A H V$ infection when exposed to BCAHV. Data represent average mortality $\pm S E M$. Values with different letters indicate statistically significant means $(p \leq 0.05)$.

In the current study, when naïve blue catfish fingerlings and survivors from previous BCAHV infection were exposed to BCAHV, significantly higher mortality in the naïve fish in comparison with the survivors were observed (Figure 4). This observation indicated an immune response afforded from a primary BCAHV infection. Presence of BCAHV in the infected fish were confirmed by observing characteristic CPEs as mentioned before. Immune responses to viral infections can be non-specific or specific depending on virus interaction with the hosts. Non-specific responses are seen early during infection and involves the activity of natural killer cells and interferons. Specific immune responses (humoral and cell-mediated) are responsible for maintaining immunity against virus reinfection [28]. Development of immune response subsequent to viral infections were reported in many fish viruses. High antibody titers were observed in the survivors of tilapia lake virus infection [29]. Similarly, significant expression of immune genes was observed in the case of koi carps infected with koi herpesvirus [30]. Immune responses elicited by the host in response to viral infections are exploited towards vaccine designing and modification $[31,32]$ and can be utilized in the case of BCAHV as well.

\section{Conclusion}

All the six Rivers's postulates have been fulfilled by BCAHV and was verified as the primary etiological agent of the infection in blue catfish. Therefore, causality of infection in blue catfish was proved to be due to BCAHV and eliminated the possibilities of all other pathogens. Verification of Rivers's postulates is essential to authenticate the causation of a disease as virus especially with a new or emerging infections. Confirmation of the pathogen further supports pathogendirected treatments and reduce the time and efforts given in misidentification. Validation on the causality of infection in blue catfish will help in advancing diseases diagnosis, and effective management strategies including vaccine development and identification of effective antivirals.

\section{Acknowledgements}

The authors thank Lester Khoo, Nicholas B. D. Phelps, Ganesh Kumar, Brian Bosworth, and Rodney Morris for their guidance and technical support. This study was funded by the Mississippi Agricultural and Forestry Experiment Station (MAFES) Strategic Research Initiative (CRIS project \#MIS371932), United States Department of AgricultureAgricultural Research Service-Catfish Health Initiative (CRIS 6402-31320-002-02), and the Delta Research and Extension Center, Stoneville, MS. The research findings documented in the publication are those of the author (s) and do not reflect the view of the United States Department of Agriculture.

\section{References}

[1] Kibenge, F. S. B. (2016). Determinants of emergence of viral diseases in aquaculture. In Aquaculture Virology. Edited by Kibenge FSB, Godoy MG. Elsevier Inc., Academic Press; 95116.

[2] Rodgers, C., Mohan, C., \& Peeler, E. (2011). The spread of pathogens through trade in aquatic animals and their products. Scientific and technical review - International Office of Epizootics, 30, 241-256.

[3] Kim, H. J., \& Kwon, S. R. (2013). Evidence for two koi herpesvirus (KHV) genotypes in South Korea. Diseases of Aquatic Organisms, 104, 197-202.

[4] Phelps, N. B. D., M. E. Craft, D. Travis, K. Pelican, \& Goyal, S. M. (2014). Risk-based management of viral hemorrhagic septicemia virus in Minnesota. North American Journal of Fisheries Management, 34, 373-379.

[5] Kibenge, F. S. B. (2019). Emerging viruses in aquaculture. 
Current Opinion in Virology, 34, 97-103.

[6] Horsfall, F. L. (1965). Thomas Milton Rivers, September 3, 1888-May 12, 1962. Biographical Memoirs of the National Academy of Sciences, 38, 263-294.

[7] Gelderblom, H. R. (1996). Structure and Classification of Viruses. In: Baron S, editor. Medical Microbiology. 4th ed. Galveston (TX): University of Texas Medical Branch at Galveston; 1996. Chapter 41.

[8] Lecoq, H. (2001). Discovery of the first virus, the tobacco mosaic virus: 1892 or 1898 ? Proceedings of the Academy of sciences, 324 (10), 929-933.

[9] Koonin, E. V., \& Starokadomskyy, P. (2016). Are viruses alive? The replicator paradigm sheds decisive light on an old but misguided question. Studies in history and philosophy of biological and biomedical sciences, 59, 125-134.

[10] Leland, D. S., \& French, M. L. V. (1988). Virus isolation and identification. In: Laboratory Diagnosis of Infectious Diseases Principles and Practice. Springer, New York, NY.

[11] Leland, D. S., \& Ginocchio, C. C. (2007). Role of cell culture for virus detection in the age of technology. Clinical Microbiology Review, 20, 49-78.

[12] Hsiung, G. D. (1984). Diagnostic virology: from animals to automation. Yale Journal of Biology and Medicine, 57, 727733 .

[13] Koch, R. (1884). The etiology of tuberculosis. Reports from the Imperial Office of Public Health, 2, 1-88.

[14] Rivers, T. M. (1937). Viruses and Koch's postulates. Journal of Bacteriology, 33, 1-12.

[15] Hanson, L., Dishon, A., \& Kotler, M. (2011). Herpesviruses that infect fish. Viruses, 3 (11), 2160- 2191.

[16] Hanson, L., Doszpoly, A., van Beurden, S. J., de Oliveira Viadanna, P. H., \& Waltzek, T. (2016). Alloherpesviruses of fish. In F. S. B. Kibenge \& M. G. Godoy (Eds.), Aquaculture Virology (pp. 153-172). Cambridge, MA: Academic Press.

[17] Aarattuthodiyil, S., \& Dharan, V. (2019). Viruses impacting the catfish industry. National Warmwater Aquaculture Center News, 16 (1), 10-11.

[18] Dharan, V., Khoo, L., Phelps, N. B. D., Kumar, G., Steadman, J., Bosworth, B., \& Aarattuthodi, S. (2021). An investigation into the pathogenesis of blue catfish alloherpesvirus in ictalurid catfish. Journal of the World Aquaculture Society. https://doi.org/10.1111/jwas.12850.

[19] Hanson, L. A., Rudis, M. R., Vasquez-Lee, M., \& Montgomery, R. D. (2006). A broadly applicable method to characterize large DNA viruses and adenoviruses based on the DNA polymerase gene. Virology Journal, 3, 28.

[20] Subramaniam, K., Venugopalan, A., Davison, A. J., Griffin, M. J., Ford, L., Waltzek, T. B., \& Hanson, L. (2019).
Complete genome sequence of an Ictalurid herpesvirus 1 strain isolated from blue catfish (Ictalurus furcatus). Microbiology Resource Announcements, 8 (15), e00082-19.

[21] Silverstein, P. S., Van Santen, V. L., Nusbaum, K. E., \& Bird, R. C. (1998). Expression kinetics and mapping of the thymidine kinase transcript and an immediate-early transcript from channel catfish virus. Journal of Virology, 72, 39003906 .

[22] Silverstein, P. S., Bosworth, B. G., \& Gaunt, P. S. (2008). Differential susceptibility of blue catfish, Ictalurus furcatus (Valenciennes), channel catfish, I. punctatus (Rafinesque), and blue $\mathrm{x}$ channel catfish hybrids to channel catfish virus. Journal of Fish Diseases, 31, 77-79.

[23] Evans, A. S. (1976). Causation and disease: the Henle-Koch postulates revisited. The Yale Journal of Biology and Medicine, 49 (2), 175-195.

[24] Fijan, N. N., Welborn, T. L. J., \& Naftel, J. P. (1970). An acute viral disease of channel catfish. US Bureau of Sport Fisheries and Wildlife Technical Paper, 43, 11 pp.

[25] Wolf, K., \& Darlington, R. W. (1971). Channel catfish virus: A new herpesvirus of ictalurid fish. Journal of Virology, 8(4), 525-533.

[26] Bowser, P. R., \& Plumb, J. A. (1980). Growth rates of a new cell line from channel catfish ovary and channel catfish virus replication at different temperatures. The Canadian Journal of Fisheries and Aquatic Sciences, 37, 871-873.

[27] Eiring, A. G., \& Scher ER, W. F. (1961). Appearance of persistently cytopathic Eastern and Western encephalitis viruses after "blind" passage in cultures of L mouse fibroblasts. Journal of Immunology, 87, 96-105.

[28] Klimpel, G. R. (1996). Immune Defenses. In: Baron S, editor. Medical Microbiology. 4th edition. Galveston (TX): University of Texas Medical Branch at Galveston; 1996. Chapter 50.

[29] Tattiyapong, P., Dechavichitlead, W., Waltzek, T. B., \& Surachetpong, W. (2020). Tilapia develop protective immunity including a humoral response following exposure to tilapia lake virus. Fish \& Shellfish Immunology, 106, 666-674.

[30] Hwang, J. A., Kim, J. E., Kim, H. S., \& Lee, J. H. (2017). Immune response to koi herpesvirus (KHV) of koi and koi $\times$ red common carp (Cyprinus carpio). Development \& reproduction, 21 (4), 361-370.

[31] Levine, M. M., \& Sztein, M. B. (2004). Vaccine development strategies for improving immunization: The role of modern immunology. Nature Immunology, 5, 460.

[32] Shoemaker, C. A., Klesius, P. H., Evans, J. J., \& Arias, C. R. (2009). Use of modified live vaccines in aquaculture. Journal of World Aquaculture Society, 40, 573-585. 